\title{
Efficacy and safety of endoscopic balloon dilatation of esophageal strictures without fluoroscopy: a pilot study
}

Mürşit Dincer, Muzaffer Akinci

Department of General Surgery, Istanbul Haseki Training and Research Hospital, Istanbul, Turkey

Submitted: 28 August 2018

Accepted: 12 September 2018

Arch Med Sci Civil Dis 2018; 3: e92-e94

DOI: https://doi.org/10.5114/amscd.2018.79432

Copyright $\odot 2018$ Termedia \& Banach

\section{Introduction}

Introduction: Esophageal strictures can be caused by malignancy, congenital stenosis, motility disorders or benign strictures. Endoscopic balloon dilatation is a simple procedure with low complication rates to treat gastrointestinal strictures. This study aims to analyze indications and results of balloon dilatation without fluoroscopy.

Material and methods: The patients who underwent pneumatic balloon dilatation (PBD) for esophageal stricture were included in the study. The demographic characteristics of the patients, indications for PBD, number of operations and complications were recorded.

Results: Twelve patients were included in this pilot study. The most common cause of esophageal strictures was malignancy. In this group, PBD was performed before stenting in the patients who were planned to receive neoadjuvant therapy, had locally advanced esophageal cancer or inoperable esophageal cancer, and complained of difficulty swallowing. Three patients underwent PBD due to achalasia. One of these patients underwent PBD 3 times due to recurrence of symptoms during the follow-up period. The success rate of PBD in this study was $91.6 \%$. The success rate for the patients who underwent PBD for the first time was $83.3 \%$. None of the patients who underwent endoscopic balloon dilatation had major complications (such as massive bleeding and perforation) or procedural mortality.

Conclusions: Endoscopic balloon dilatation without fluoroscopy performed by experienced endoscopists is an effective and safe method for the treatment of esophageal strictures. Successful results are obtained with low complication rates in experienced centers.

Key words: balloon dilatation, esophageal strictures, fluoroscopy.

\section{Introduction}

Esophageal strictures can be caused by malignancies, congenital anomalies, motility disorders, or benign reasons. The most common causes of esophageal stricture in adults are gastroesophageal reflux disease and esophageal cancer. Eighty percent of benign esophageal strictures occur after mucosal injury secondary to chronic acid exposure [1, 2]. Pneumatic balloon dilatation is a technique that is used in esophageal strictures, has low complication rates compared to surgical procedures and can be performed more easily and safely [3]. In this pilot study, we aimed to present the causes of esophageal strictures and the effectiveness of balloon dilatation procedures without fluoroscopy.

\author{
Corresponding author: \\ Dr. Mürşit Dincer \\ Department of General \\ Surgery \\ Istanbul Haseki \\ Training and \\ Research Hospital \\ St Aksaray Fatih \\ 34100 Istanbul, Turkey \\ Phone: +90 5446422820 \\ E-mail: drmursitdincer@ \\ gmail.com
}




\section{Material and methods}

The patients who underwent gastroscopy between November 2015 and December 2016 were retrospectively examined. Twelve patients who underwent pneumatic balloon dilatation (PBD) for esophageal stricture were included in the study. The demographic characteristics of the patients, indications for PBD, number of operations and complications were recorded. Endoscopic balloon dilatation was performed under sedation without fluoroscopy in the endoscopy unit. In the patients who had an esophageal stricture during the gastroscopy and were planned to undergo PBD, it was passed to the distal part of the stricture with the aid of a guide wire. The balloon catheter was advanced over the guide wire. An achalasia balloon with a diameter of $30 \mathrm{~mm}$ was used in all patients. The balloon was inflated with air. The patients were called for a checkup in the first month after the dilatation procedure. In the patients who were symptomatic and had an esophageal stricture during the gastroscopy, PBD was performed again. In the patients who were symptomatic in subsequent checks, the gastroscopy and PBD were repeated.

\section{Results}

Twelve patients were included in this pilot study. Nine $(75 \%)$ patients were male and 3 (25\%) patients were female. The mean age of the patients was 52.2 (29-89) years. The most common cause of esophageal strictures was malignancy (Table I). In this group, PBD was performed before stenting in the patients who were planned to receive neoadjuvant therapy, had locally advanced esophageal cancer or inoperable esophageal cancer, and complained of difficulty swallowing. In 1 patient, the guide wire could not be passed to the distal part of the stricture despite PBD. For this reason, stenting could not be performed. This patient underwent surgical gastrostomy. Three patients underwent PBD due to achalasia. One of these patients underwent PBD 3 times due to recurrence of symptoms during the follow-up period. The patients in other groups which underwent PBD did not require re-dilatation during the follow-up period. The success rate of PBD in this study was $91.6 \%$. The success rate for the patients who underwent PBD for the first time was $83.3 \%$. None of the patients who underwent endoscopic balloon dilatation had major complications (such as massive bleeding and perforation) or procedural mortality.

\section{Discussion}

Pneumatic balloon dilatation is the most common treatment option for achalasia. Achalasia is a motility disorder characterized by impaired low- er esophageal sphincter loosening and abnormal esophageal peristalsis. It is caused by the loss of ganglion cells in the esophageal myenteric plexus that regulate loosening of the lower esophageal sphincter and esophageal peristalsis [4]. Endoscopic balloon dilatation is an effective treatment for achalasia [5, 6]. Balloon dilatation for the treatment of achalasia was first described in the $17^{\text {th }}$ century [7]. Treatment options for achalasia include surgery, endoscopic balloon dilatation, and endoscopic injection of botulinum toxin into the lower esophageal sphincter [8]. The PBD ranks first in non-surgical treatment options [9]. When it is performed by experienced endoscopists, it has been proven to be reliable and is the most cost-effective method [7]. However, it is associated with a relatively high perforation rate, and repeated treatments may be needed [10]. The long-term success rate in patients undergoing balloon dilatation due to achalasia has been reported to be 85\% [11]. Boeckxstaens et al. reported that the long-term outcomes in patients undergoing PBD and myotomy due to achalasia were similar [12]. The most important complication of pneumatic balloon dilatation is the development of perforation during the procedure. The perforation rate is approximately $2.5 \%$ to $5 \%$. Balloon instability and high pressure balloon inflation are the main factors responsible for perforation $[6,7,11,13]$. The most common chronic complication after PBD is gastroesophageal reflux disease [7]. However, gastroesophageal reflux disease after PBD responds well to proton pump inhibitor therapy [14]. Less frequent complications such as intramural hematoma, gastric cardia diverticula, and angina can also be seen after PBD [6]. In our study, major complications did not develop.

In a meta-analysis published by Wang et al., when 1-year outcomes of patients undergoing botulinum toxin injection and balloon dilatation for the treatment of achalasia were compared, it was found that PBD was more successful than botulinum toxin injection in terms of recurrence of symptoms [15]. In a study of Jung et al. comparing the long-term outcomes of PBD and botulinum toxin, PBD was found to be more effective [16]. However, there are also studies in the literature that have different results on this subject [17].

Table I. PBD Indications

\begin{tabular}{|lcc|}
\hline Indications & $\begin{array}{c}\text { No. of } \\
\text { patients }\end{array}$ & Percent \\
\hline Esophageal carcinoma & 6 & 50 \\
\hline Achalasia & 3 & 25 \\
\hline $\begin{array}{l}\text { Esophagojejunal or gastrojejunal } \\
\text { anastomosis stricture }\end{array}$ & 2 & 16.6 \\
\hline Benign stricture (peptic ulcer) & 1 & 8.33 \\
\hline
\end{tabular}


Eighty percent of benign esophageal strictures occur after mucosal injury secondary to chronic acid exposure. Various reasons such as Schatzki ring, esophageal web, exposure to caustic substances, and radiotherapy may lead to benign esophageal strictures [1]. Another usage area of PBD is benign anastomotic strictures after surgery. Symptomatic benign anastomotic stricture in patients undergoing gastrectomy can be seen up to $16.0 \%$. Benign anastomotic strictures may develop due to many factors, such as anastomotic leakage and stapled anastomosis. The PBD is a reliable and effective method for benign anastomotic strictures [3, 18]. In our study, 2 patients who underwent gastric surgery and developed benign anastomotic stricture were successfully treated with balloon dilatation. During the follow-up period, the patients had no symptoms which would indicate esophageal stricture.

Balloon dilatation can also be performed for dysphagia due to esophageal cancer. Because of perforation and siding risks, we often do not perform balloon dilatation in patients with esophageal cancer. However, when applying covered self-expandable metal stents in palliative treatment of dysphagia due to malignant esophageal strictures, sometimes we encounter esophageal stricture that can hardly allow the passage of a guide wire. In these patients, we place a stent after PBD to perform stenting more effectively. In this study, PBD was successfully performed for this indication before stenting in 6 patients.

This study has some limitations. Firstly, our study is retrospective. Secondly, there is a small number of patients in our study. Some patients were lost during the follow-up period because we needed the help of other institutions in diagnosing esophageal motility disorders. Another limitation is that our follow-up period is relatively short. This pilot study has shown that balloon dilatation is an effective and safe method without the use of fluoroscopy. However, prospective studies with longer follow-up and larger patient numbers are required to support these results.

In conclusion, endoscopic balloon dilatation without fluoroscopy performed by experienced endoscopists is an effective and safe method for the treatment of esophageal strictures. Successful results are obtained with low complication rates in experienced centers.

\section{Conflict of interest}

The authors declare no conflict of interest.

\section{References}

1. Samanta J, Dhaka N, Sinha SK, Kochhar R. Endoscopic incisional therapy for benign esophageal strictures: technique and results. World J Gastrointest Endosc 2015; 7: 1318-26.

2. Pieczarkowski S, Woynarowski M, Landowski P, et al. Endoscopic therapy of oesophageal strictures in children - a multicentre study. Gastroenterology Rev 2016; 11: 194-9.

3. Lee HJ, Park W, Lee $H$, et al. Endoscopy-guided balloon dilation of benign anastomotic strictures after radical gastrectomy for gastric cancer. Gut Liver 2014; 8: 394-9.

4. Park SK, Hong SJ, Han JP, et al. Changes in pressure waves after endoscopic intervention in patients with achalasia: a focus on peristaltic recovery of the esophageal body. Turk J Gastroenterol 2016; 27: 4-9.

5. Cox J, Buckton GK, Bennett JR. Balloon dilatation in achalasia: a new dilator. Gut 1986; 27: 986-9.

6. Dobrucali A, Erzin Y, Tuncer M, Dirican A. Long-term results of graded pneumatic dilatation under endoscopic guidance in patients with primary esophageal achalasia. World J Gastroenterol 2004; 10: 3322-7.

7. Dughera L, Chiaverina M, Cacciotella L, Cisarò F. Management of achalasia. Clin Exp Gastroenterol 2011; 4: 33-41.

8. Alderliesten J, Conchillo JM, Leeuwenburgh I, Steyerberg EW, Kuipers EJ. Predictors for outcome of failure of balloon dilatation in patients with achalasia. Gut 2011; 60: 10-6.

9. Chuah SK, Wu KL, Hu TH, Tai WC, Changchien CS. Endoscope-guided pneumatic dilation for treatment of esophageal achalasia. World J Gastroenterol 2010; 16: 411-7.

10. Hong D, Pescarus R, Khan R, Ambrosini L, Anvari M, Cadeddu M. Early clinical experience with the POEM procedure for achalasia. Can J Surg 2015; 58: 389-93.

11. Vanuytsel $T$, Lerut $T$, Coosemans $W$, et al. Conservative management of esophageal perforations during pneumatic dilation for idiopathic esophageal achalasia. Clin Gastroenterol Hepatol 2012; 10: 142-9.

12. Boeckxstaens GE, Annese V, des Varannes SB, et al. Pneumodilation versus laparoscopic Heller myotomy for idiopathic achalasia. N Engl J Med 2011; 364: 1807-16.

13. Kim H. Gastroplasty for esophageal perforation after endoscopic balloon dilatation for achalasia: two cases. J Korean Med Sci 2014; 29: 739-42.

14. Min YW, Lee JH, Min BH, Lee JH, Kim JJ, Rhee PL. Association between gastroesophageal reflux disease after pneumatic balloon dilatation and clinical course in patients with achalasia. J Neurogastroenterol Motil 2014; 20: 212-8.

15. Wang L, Li YM, Li L. Meta-analysis of randomized and controlled treatment trials for achalasia. Dig Dis Sci 2009; 54: 2303-01.

16. Jung $\mathrm{HE}$, Lee JS, Lee $\mathrm{TH}$, et al. Long-term outcomes of balloon dilation versus botulinum toxin injection in patients with primary achalasia. Korean J Intern Med 2014; 29: 738-45.

17. Patti MG, Fisichella PM, Perretta S, et al. Impact of minimally invasive surgery on the treatment of esophageal achalasia: a decade of change. J Am Coll Surg 2003; 196: 698-703.

18. Dolce CJ, Dunnican WJ, Kushnir L, Bendana E, Ata A, Singh TP. Gastrojejunal strictures after Roux-en-Y gastric bypass with a 21-MM Circular Stapler. JSLS 2009; 13: 306-11. 